\title{
Análisis de los valores sociales y de género en la publicidad gráfica de automóviles a partir de la interpretación de los escolares de tercer ciclo de primaria
}

Rafael Moreno Díaz | proferafa25@hotmail.com

UNIVERSIDAD DE CÓRDOBA

Resumen: El presente trabajo ofrece los resultados de una investigación acerca de los valores sociales y de género, percibidos en los anuncios de automóviles por el alumnado de educación primaria. En dicho estudio, realizado en dos colegios de Córdoba y uno de Jaén, participaron un total de 289 alumnos y alumnas del tercer ciclo de educación primaria. El propósito inicial es explorar cómo la representación del hombre y de la mujer se realiza en la publicidad de automóviles, aspecto encaminado a analizar si ambos géneros son tratados de la misma manera o si, por el contrario, se asignan determinados valores a hombres y mujeres.

Palabras clave: publicidad, valores, estereotipos de género, sociedad.

Abstract: This essay offers the results obtained on a research in which social values and gender issues were analyzed through cars commercials by students of Elementary Education. In the mentioned study, conducted in two schools of Cordoba and Jaen, a total of 289 students from the fifth and six grade of Elementary Education took part in it. The main focus is to explore the male and female representations on the automotive commercials, an aspect that should show whether or not both genders are portrayed on the same way or using specific values.

Key words: advertising, values, gender stereotypes, society. 


\section{Introducción}

La publicidad se ha instalado en nuestras vidas de manera inequívoca e incuestionable. Aquellas palabras de Vance Packard (2007) en las que nos mostraba que ya no comíamos naranjas sino vitalidad, aún siguen vigentes en nuestros días, pues hoy, todo lo que compramos, vestimos o comemos se encuentra mediatizado por el fenómeno publicitario, que nos propone e, incluso, dicta modelos a seguir, y que inciden de algún modo en nuestros pensamientos y conductas. El problema, sin embargo, no son los medios de comunicación o la propia publicidad, sino que estos, se han hecho, según Racionero (2004: 299) "omnipresentes, ya que ocupan gran parte del espacio y del tiempo de esos medios, y con su ubicuidad nos bombardean con multitud de noticias, informaciones y mensajes que, lejos de ser asépticos y neutrales, están cargados de estímulos persuasivos". La publicidad, a través de diferentes estrategias persuasivas, persigue influir no solo en la actitud de compra sino también en el comportamiento de los ciudadanos en cuanto consumidores, pues, tal y como dice Sáinz (2002: 29), "todo mensaje publicitario lleva implícitas unas propuestas, más o menos intensas, de modos de conducta a través de los personajes, las escenas, las figuras o los textos". De igual modo, Racionero (2004: 296) nos alerta de que "la tendencia a adquirir productos por encima de las verdaderas necesidades no está cuestionada... sino que se considera de 'buen gusto' la acción de consumir", actitud que es reforzada por los mecanismos persuasivos publicitarios.

Por otro lado, el discurso publicitario, en palabras de Correa, Guzmán y Aguaded (2000: 56), "nos arrastra a una pasividad que niega todo tipo de diálogo y que solo se torna activo en el acto final de la compra del producto anunciado, en una automatización del comportamiento que nos han planificado de antemano y al que masivamente contestamos de forma acrítica". Puede parecer exagerado, pero es posible que en la actualidad el poder de la publicidad sea tal que muchas de las decisiones que tomamos estén condicionadas por ella, pues, como apunta Eguizábal (2009: 253), "la publicidad se encarga de controlar el ocio, de dirigir el comportamiento en el ámbito de la intimidad. Nos explica cuándo y de qué manera se obtiene el obligatorio disfrute". Hasta tal punto es poderosa la publicidad que elementos tan importantes como los valores personales y sociales se encuentran insertos en el discurso publicitario para ser utilizados con fines comerciales.

La publicidad es un medio válido y eficaz para transmitir información comercial, pero, al mismo tiempo, también lo es para ejercer un control de masas, es decir, una forma más de sancionar lo que es bueno o malo, lo necesario y lo innecesario, lo aceptable y lo rechazable. $Y$ es que, a pesar del conservadurismo ideológico que transmite en sus mensajes, la publicidad "se ve abocada a una incesante remodelación de su discurso, remodelación que lleva a cabo cada vez que surge una tendencia nueva, o aparece un cambio social, o se produce una transformación en las costumbres" (Rey, 2008: 14). Estas transformaciones, para las que la publicidad no tiene en cuenta ni la edad ni las características del público que recibirá los impactos, se suelen producir en beneficio propio, como ya afirma el autor citado anteriormente; nunca pensando en la importancia educativa de los valores sociales. 
Es posible que en el mundo de los adultos se puedan relativizar los valores insertos en el discurso publicitario; sin embargo, no debemos olvidar que dentro del público que recibe impactos publicitarios se encuentran niños y adolescentes. Tal y como apunta Osuna (2008:173) "la publicidad está presente en la vida de los adolescentes desde su nacimiento. Han convivido con ella y la han visto evolucionar". Sin embargo, los adolescentes carecen de las herramientas que les permitan detectar las diferentes estrategias persuasivas utilizadas por los publicistas, aunque cada día asisten indefensos a la avalancha de anuncios seductores que se presenta ante sus ojos. Por tanto, podemos afirmar que no solo los valores presentes en los anuncios están en contraposición con aquellos que se transmiten dentro del seno familiar o de la escuela, sino que también dichos valores pueden influir en la futura configuración de la personalidad del adolescente. $Y$ es que, como apuntan Eguizábal (2009) o Sáinz (2002) los medios de comunicación social ejercen en nuestra sociedad una importante función en la transmisión de valores sociales y educativos, ofrecen al público en general formas de vida y actitudes. A través de sus imágenes pueden imponer modas, transformar normas de conducta y/o consolidar valores. De este modo no es de extrañar que diversos estudios coincidan en afirmar que "a los 18 meses, los niños son capaces de reconocer logotipos, y antes de cumplir los 2 años, ya piden los productos que quieren nombrándolos por su marca [...] hacia los tres años y medio empiezan a creer que la marcas expresan sus características personales" (Schor, 2006:31).

Dentro de los estereotipos que la publicidad contribuye a perpetuar socialmente se encuentran los que hacen referencia a los modelos masculino y femenino a partir de las imágenes insertas en los anuncios. De este modo, tal y como apuntan Correa, Guzmán y Aguaded (2000: 14) "en la publicidad hay una estereotipia fundamental que envuelve el concepto de hombre y mujer. El modelo de hombre que aquella propone es diametralmente opuesto al modelo de mujer, hecho éste que ayuda también a establecer una socialización de género y estatus". Así, Rodrigo Martín (2011), Wood (2008) o Rodríguez, Matud y Espinosa (2008) nos muestran que el hombre sigue siendo representado en espacios abiertos, realizando actividades de riesgo y asociado a significados como conquistador, dominante y competitivo; mientras que a la mujer se la ubica dentro de espacios cerrados, realizando actividades domésticas o asociándose con frecuencia a valores como la belleza, el cariño o la fragilidad. Más concretamente, según Cano (2001: 59) "podemos decir que el campo de lo privado, de puertas para adentro, suele corresponder a la mujer, mientras que las relaciones con el exterior son del dominio masculino".

Esta situación, años después, parece no haber cambiado mucho $y$, como se pretende demostrar con esta investigación, aún hoy se siguen utilizando valores diferentes y contrapuestos a través de las imágenes publicitarias para referirse al hombre y a la mujer, al mundo masculino y al mundo femenino, encasillándolos dentro de unas acciones y características diferenciadas que no contribuyen sino a perpetuar estereotipos asociados a ambos géneros. 


\section{Objetivo de la investigación}

En la investigación se pretende conocer los valores que los escolares de tercer ciclo de Educación Primaria asocian con las personas que aparecen en cuatro anuncios de publicidad gráfica seleccionados de una temática cercana a sus intereses como es la publicidad de automóviles. En este sentido, lo que nos interesa conocer son los valores asignados tanto a hombres como a mujeres, independientemente de que la persona que aparezca en el anuncio sea un personaje famoso o no.

A continuación, una vez conocidos los valores predominantes, se trataría de saber si los estereotipos asociados a los géneros masculino y femenino continúan en la mente de los escolares o, por el contrario, hay una tendencia a la superación de esquemas de tipo sexista.

\section{Pruebas y metodología de trabajo}

La investigación se llevó a cabo durante dos cursos escolares, contando con la participación del alumnado de quinto y sexto curso de Educación Primaria de dos centros de Córdoba y otro de Jaén. En total intervinieron 289 sujetos en el trabajo, 145 chicos y 144 chicas, repartidos de la siguiente manera:

- Colegio 1.93 alumnos, repartidos en 47 chicos y 46 chicas.

- Colegio 2. 100 alumnos, repartidos en 51 chicos y 49 chicas.

- Colegio 3. 96 alumnos, repartidos en 47 chicos y 49 chicas.

Como metodología de investigación se utilizó la aportada por Sáinz (2002), en el sentido de que para llevar a cabo la interpretación de los valores asociados a las figuras masculina y femenina en los mensajes icónicos se ofrezca a los sujetos una relación de valores contrapuestos en un cuestionario, de modo que, observando el anuncio proyectado en pantalla, eligieran aquel que consideren que se adecua más a lo que cada uno piensa de manera espontánea. De este modo, el cuestionario ofrecido, para cada uno de los cuatro anuncios, constaba de 20 valores contrapuestos, siendo los siguientes: 1 . valiente-cobarde, 2. débil-fuerte, 3. ganador-perdedor, 4. seguro-inseguro, 5. sumiso-dominante, 6. atrevidotímido, 7. rebelde-obediente, 8. joven-mayor, 9. serio-alegre, 10. nervioso-tranquilo, 11. sincero-falso, 12 . responsable-despreocupado, 13 . individualista-solidario, 14 . sensualrecatado, 15. egoísta-generoso, 16. hogareño-callejero, 17. cariñoso-frío, 18. educadodescortés, 19. duro-suave, 20. agresivo-pacífico. Hay que indicar que, en el cuestionario dedicado a los anuncios con protagonistas femeninas, los valores indicados, lógicamente, se proponían en femenino.

A la hora de elegir la temática de los anuncios, fue necesario revisar la literatura acerca de los intereses del alumnado en relación a la publicidad. En este sentido, Sánchez, Megías y 
Rodríguez (2004) o más concretamente Ortiz (2008) coinciden en incluir a los automóviles como uno de los sectores económicos más frecuentemente implicados en la publicidad de los jóvenes y adolescentes, junto a la cosmética, telefonía móvil, internet y alimentación. De este modo, si bien la muestra participante no es el público destinatario de dichas campañas publicitarias, el automóvil representa para ellos y ellas un objeto de deseo, de posesión futura.

Puesto que fueron 4 anuncios, dos con personajes masculinos y otros dos con femeninos, en total nos encontramos con 80 respuestas por cada participante y con un total de 23.120 valores elegidos por el alumnado participante. Una vez codificadas las respuestas, se procedió al análisis cuantitativo de la muestra, elaborando una tabla de frecuencias que nos permita obtener datos acerca de los valores que se asocian a uno u otro género, para, finalmente, realizar una interpretación de los valores que se asocian con el género masculino y los que lo hacen con el femenino, centrándonos en los que adquieren el rango de estereotipo. Asimismo, para verificar la significación en la relación entre variables se utilizó el estadístico chi- cuadrado.

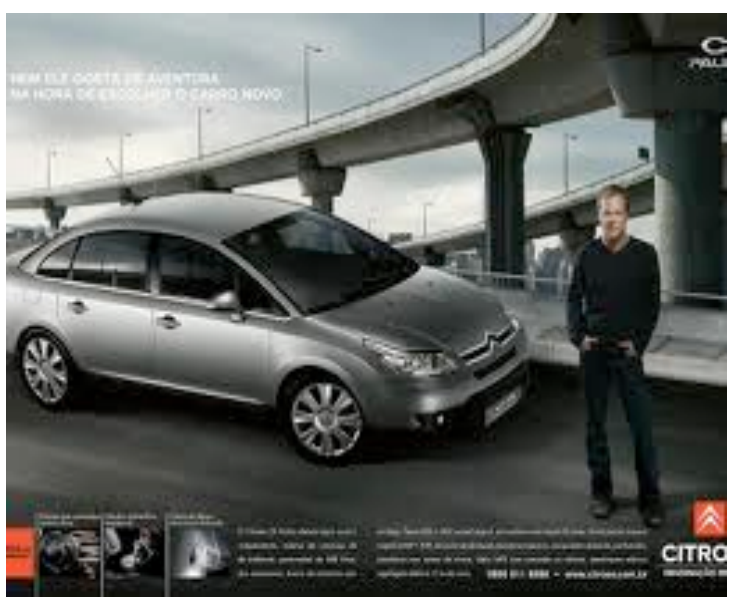

Anuncio 1. Automóvil Citroën

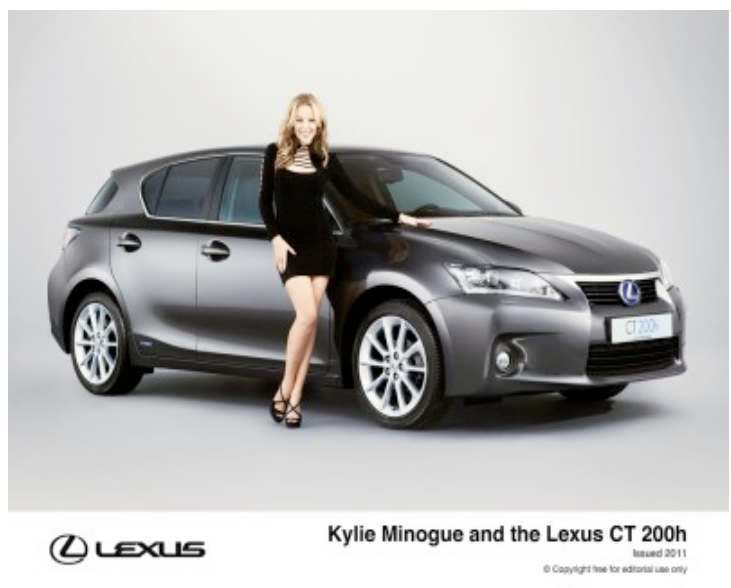

Anuncio 2. Automóvil Lexus 


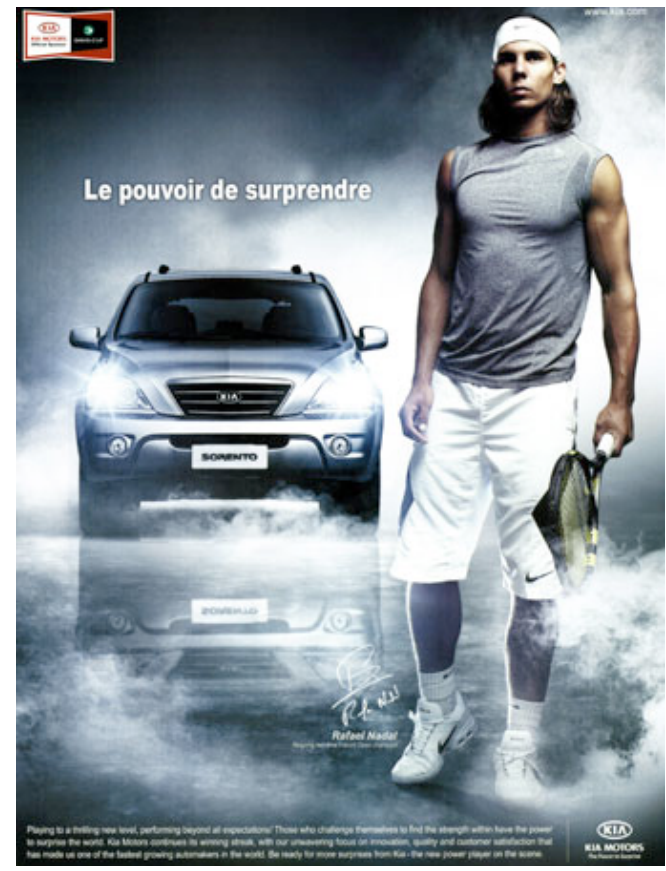

Anuncio 3. Automóvil Kia hombre.

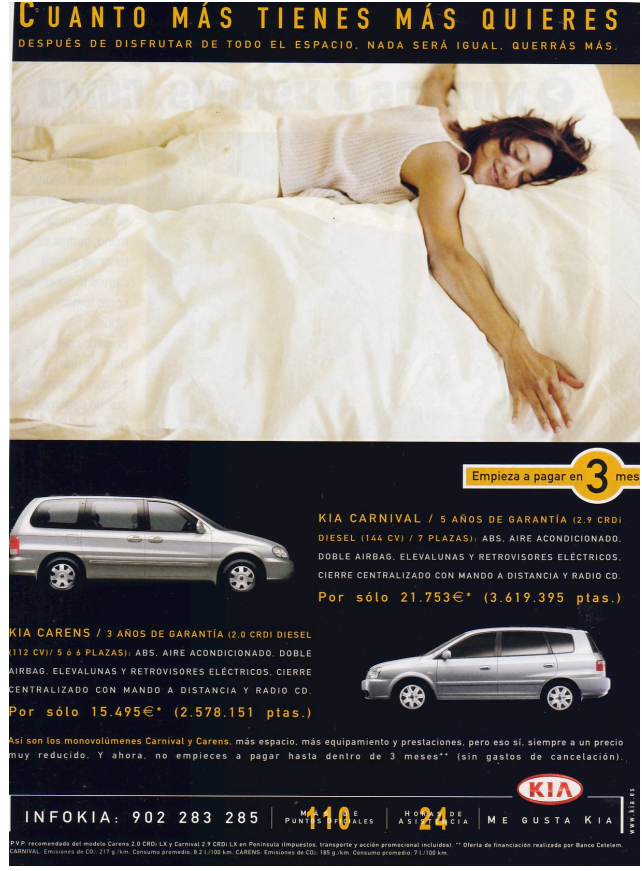

Anuncio 4. Automóvil Kia mujer.

\section{Resultados obtenidos}

Para favorecer el análisis y la comprensión de los resultados, se estudian por separado cada uno de los anuncios utilizados, incluyéndose en las tablas posteriores tanto los resultados obtenidos para cada uno de los valores, como las diferencias existentes entre ambos. De este modo, una vez finalizado el proceso, estaremos en disposición de conocer cuáles son los valores presentes en los anuncios publicitarios a través de las respuestas dadas por el alumnado, así como la diferencia que aparece a la hora de asignar unos valores u otros a los anuncios, en función del género de las personas que aparecen en el anuncio.

\subsection{Anuncios Citroën y Lexus}

\begin{tabular}{|l|l|l|l|}
\hline Pregunta / Valores & Valor 1 & Valor 2 & Diferencia \\
\hline 1. Valiente / Cobarde & $75 \%$ & $25 \%$ & Valiente $(50 \%)$ \\
\hline 2. Débil / Fuerte & $5,4 \%$ & $94,6 \%$ & Fuerte $(89,2 \%)$ \\
\hline 3. Ganador / Perdedor & $98,7 \%$ & $1,3 \%$ & Ganador $(97,4 \%)$ \\
\hline 4. Seguro / Inseguro & $91,7 \%$ & $8,3 \%$ & Seguro $(83,4 \%)$ \\
\hline 5. Sumiso / Dominante & $12,5 \%$ & $87,5 \%$ & Dominante $(83,4 \%)$ \\
\hline 6. Atrevido / Tímido & $97,4 \%$ & $2,6 \%$ & Atrevido $(94,8 \%)$ \\
\hline 7. Rebelde / Obediente. & $79,5 \%$ & $20,5 \%$ & Rebelde $(59 \%)$ \\
\hline 8. Joven / Mayor. & $78,4 \%$ & $21,6 \%$ & Joven $(56,8 \%)$ \\
\hline 9. Serio / Alegre. & $75,8 \%$ & $24,2 \%$ & Serio $(51,6 \%)$ \\
\hline 10. Nervioso / Tranquilo. & $37,7 \%$ & $62,3 \%$ & Tranquilo $(24,6 \%)$ \\
\hline
\end{tabular}




\begin{tabular}{|l|l|l|l|}
\hline 11. Sincero / Falso. & $53,7 \%$ & $46,3 \%$ & Sincero (7,4\%) \\
\hline 12. Responsable / Despreocupado & $41,7 \%$ & $58,3 \%$ & Despreocupado (16,6\%) \\
\hline 13. Individualista / Solidario & $81,7 \%$ & $18,3 \%$ & Individualista (63,4\%) \\
\hline 14. Sensual / Recatado & $64,3 \%$ & $35,7 \%$ & Sensual (28,6\%) \\
\hline 15. Egoísta / Generoso & $64,7 \%$ & $35,3 \%$ & Egoísta (29,4\%) \\
\hline 16. Hogareño / Callejero & $25,6 \%$ & $74,4 \%$ & Callejero (48,8\%) \\
\hline 17. Cariñoso / Frío & $19,2 \%$ & $80,8 \%$ & Frío (61,6\%) \\
\hline 18. Educado / Descortés & $46,8 \%$ & $53,2 \%$ & Descortés (6,4\%) \\
\hline 19. Duro / Suave & $92,3 \%$ & $7,7 \%$ & Duro (84,6\%) \\
\hline 20. Agresivo/ Pacífico & $69,9 \%$ & $30,1 \%$ & Agresivo (39,8\%) \\
\hline
\end{tabular}

Tabla 1. Resultados anuncio Citroën hombre.

\begin{tabular}{|c|c|c|c|}
\hline Pregunta/ Valores & Valor 1 & Valor 2 & Diferencia \\
\hline 1. Valiente / Cobarde & $32 \%$ & $68 \%$ & Cobarde $(36 \%)$ \\
\hline 2. Débil / Fuerte & $94,7 \%$ & $5,3 \%$ & Débil $(89,4 \%)$ \\
\hline 3. Ganadora / Perdedora & $38,5 \%$ & $61,5 \%$ & Perdedora (23\%) \\
\hline 4. Segura / Insegura & $39,5 \%$ & $60,5 \%$ & Insegura $(21 \%)$ \\
\hline 5. Sumisa / Dominante & $78,7 \%$ & $21,3 \%$ & Sumisa $(57,4 \%)$ \\
\hline 6. Atrevida / Tímida & $64,5 \%$ & $35,5 \%$ & Atrevida (29\%) \\
\hline 7. Rebelde / Obediente & $37,4 \%$ & $62,6 \%$ & Obediente $(25,2 \%)$ \\
\hline 8. Joven / Mayor & $93,5 \%$ & $6,5 \%$ & Joven $(87 \%)$ \\
\hline 9. Seria / Alegre & $0 \%$ & $100 \%$ & Alegre $(100 \%)$ \\
\hline 10. Nerviosa / Tranquila & $11,9 \%$ & $88,1 \%$ & Tranquila $(76,2 \%)$ \\
\hline 11. Sincera / Falsa & $90,8 \%$ & $9,2 \%$ & Sincera $(81,6 \%)$ \\
\hline 12. Responsable / Despreocupada & $72,3 \%$ & $27,7 \%$ & Responsable $(44,6 \%)$ \\
\hline 13. Individualista / Solidaria & $29,8 \%$ & $70,2 \%$ & Solidaria $(40,4 \%)$ \\
\hline 14. Sensual / Recatada & $86,1 \%$ & $13,9 \%$ & Sensual $(72,2 \%)$ \\
\hline 15. Egoísta / Generosa & $7,9 \%$ & $92,1 \%$ & Generosa $(84,2)$ \\
\hline 16. Hogareña / Callejera & $60,6 \%$ & $39,4 \%$ & Hogareña $(21,2 \%)$ \\
\hline 17. Cariñosa / Fría & $94,9 \%$ & $5,1 \%$ & Cariñosa $(89,8 \%)$ \\
\hline 18. Educada / Descortés & $96,2 \%$ & $3,8 \%$ & Educada $(92,4 \%)$ \\
\hline 19. Dura / Suave & $14,1 \%$ & $85,9 \%$ & Suave $(71,8 \%)$ \\
\hline 20. Agresiva / Pacífica & $6,3 \%$ & $93,7 \%$ & Pacífica $(87,4 \%)$ \\
\hline
\end{tabular}

Tabla 2. Resultados anuncio Lexus mujer

Tras analizar las respuestas obtenidas para el anuncio de la marca Citroën, se aprecian diferencias superiores al $50 \%$ sobre sus opuestos en los valores valiente, fuerte, ganador, seguro, dominante, atrevido, rebelde, joven, tranquilo, individualista, sensual, frío y duro. Del mismo modo, los valores serio, egoísta, callejero y agresivo superan en más de un $30 \%$ 
de las elecciones obtenidas a su término contrario. $Y$ al mismo tiempo, los valores despreocupado, sincero y descortés superan, aunque en proporciones inferiores al $30 \%$ a sus antónimos.

Respecto al anuncio de la marca Lexus, en 14 de las 20 parejas de valores contrapuestos, las diferencias superan el 50\%. Así, el alumnado suele asociar a la mujer los valores valiente, débil, ganadora, segura, joven, alegre, tranquila, sincera, sensual, generosa, cariñosa, educada, suave y pacífica. De manera similar, los términos atrevida, responsable y solidaria superan en más de un $30 \%$ a sus antónimos en las respuestas dadas por el alumnado. Y, al igual que ocurría anteriormente, únicamente tres parejas de valores contrapuestos se diferencia en menos de un 30\%, destacando los términos sumisa, obediente y hogareña a la hora de referirse al género femenino.

Comparando ahora los dos anuncios observamos que, mientras que el hombre obtiene mayores porcentajes en valores como valiente, fuerte, dominante, atrevido, serio, individualista, callejero, frío, duro o agresivo, la muestra participante suele asociar a la mujer los valores débil, joven, alegre, tranquila, sincera, responsable, solidaria, generosa, cariñosa, educada, suave y pacífica, al mismo tiempo que en casos como valentía o atrevimiento obtienen puntuaciones inferiores al anuncio de género masculino. Como puede verse, estos valores son diferentes a los anteriores y, al mismo tiempo, nos muestran ciertas diferencias a la hora de interpretar la imagen masculina y femenina que ofrece la publicidad.

\subsection{Anuncios Kia hombre y mujer}

\begin{tabular}{|l|l|l|l|}
\hline \multicolumn{1}{|c|}{ Pregunta/ Valores } & Valor 1 & Valor 2 & Diferencia \\
\hline 1. Valiente / Cobarde & $83 \%$ & $17 \%$ & Valiente (66\%) \\
\hline 2. Débil / Fuerte & $6,5 \%$ & $93,5 \%$ & Fuerte (87\%) \\
\hline 3. Ganador / Perdedor & $87,4 \%$ & $12,6 \%$ & Ganador (74,8\%) \\
\hline 4. Seguro / Inseguro & $87,4 \%$ & $12,6 \%$ & Seguro (74,8\%) \\
\hline 5. Sumiso / Dominante & $8,9 \%$ & $90,1 \%$ & Dominante (81,2\%) \\
\hline 6. Atrevido / Tímido & $92,3 \%$ & $7,7 \%$ & Atrevido (84,6\%) \\
\hline 7. Rebelde / Obediente & $64,7 \%$ & $35,3 \%$ & Rebelde (29,4\%) \\
\hline 8. Joven / Mayor & $62,7 \%$ & $37,3 \%$ & Joven (25,4\%) \\
\hline 9. Serio / Alegre & $78,1 \%$ & $21,9 \%$ & Serio (56,2\%) \\
\hline 10. Nervioso / Tranquilo & $43,6 \%$ & $56,4 \%$ & Tranquilo (12,8\%) \\
\hline 11. Sincero / Falso & $70,8 \%$ & $29,2 \%$ & Sincero (41,6\%) \\
\hline 12. Responsable / Despreocupado & $65,1 \%$ & $34,9 \%$ & Responsable (30,2\%) \\
\hline 13. Individualista / Solidario & $56,3 \%$ & $43,7 \%$ & Individualista (12,6\%) \\
\hline 14. Sensual / Recatado & $59,1 \%$ & $40,9 \%$ & Sensual (18,2\%) \\
\hline 15. Egoísta / Generoso & $63,4 \%$ & $36,6 \%$ & Egoísta (26,8\%) \\
\hline 16. Hogareño / Callejero & $26,9 \%$ & $73,1 \%$ & Callejero (46,2\%) \\
\hline 17. Cariñoso / Frío & $48,6 \%$ & $51,4 \%$ & Frío (2,8\%) \\
\hline
\end{tabular}




\begin{tabular}{|l|l|l|l|}
\hline 18. Educado / Descortés & $76,3 \%$ & $23,7 \%$ & Educado $(52,6 \%)$ \\
\hline 19. Duro / Suave & $84,3 \%$ & $15,7 \%$ & Duro $(68,6 \%)$ \\
\hline 20. Agresivo / Pacífico & $59,8 \%$ & $40,2 \%$ & Agresivo $(19,6 \%)$ \\
\hline
\end{tabular}

Tabla 3. Resultados Kia hombre.

\begin{tabular}{|l|l|l|l|}
\hline Pregunta/ Valores & Valor 1 & Valor 2 & Diferencia \\
\hline 1. Valiente / Cobarde & $17 \%$ & $83 \%$ & Cobarde (66\%) \\
\hline 2. Débil / Fuerte & $54,5 \%$ & $45,5 \%$ & Débil (9\%) \\
\hline 3. Ganadora / Perdedora & $32 \%$ & $68 \%$ & Perdedora (36\%) \\
\hline 4. Segura / Insegura & $42,6 \%$ & $57,4 \%$ & Insegura $(14,8 \%)$ \\
\hline 5. Sumisa / Dominante & $51,9 \%$ & $48,1 \%$ & Sumisa (3,8\%) \\
\hline 6. Atrevida / Tímida & $26,5 \%$ & $73,5 \%$ & Tímida (47\%) \\
\hline 7. Rebelde / Obediente & $19,4 \%$ & $80,6 \%$ & Obediente (61,2\%) \\
\hline 8. Joven / Mayor & $95,8 \%$ & $4,2 \%$ & Joven (91,6\%) \\
\hline 9. Seria / Alegre. & $24,7 \%$ & $75,3 \%$ & Alegre $(50,6 \%)$ \\
\hline 10. Nerviosa / Tranquila. & $19,5 \%$ & $80,5 \%$ & Tranquila $(61 \%)$ \\
\hline 11. Sincera / Falsa. & $90,2 \%$ & $9,8 \%$ & Sincera $(80,4 \%)$ \\
\hline 12. Responsable / Despreocupada & $77,9 \%$ & $22,1 \%$ & Responsable (55,8\%) \\
\hline 13. Individualista / Solidaria & $33,3 \%$ & $66,7 \%$ & Solidaria $(33,4 \%)$ \\
\hline 14. Sensual / Recatada & $78,7 \%$ & $21,3 \%$ & Sensual $(57,4 \%)$ \\
\hline 15. Egoísta / Generosa & $12,5 \%$ & $87,5 \%$ & Generosa $(75 \%)$ \\
\hline 16. Hogareña / Callejera & $92,3 \%$ & $7,7 \%$ & Hogareña $(84,6 \%)$ \\
\hline 17. Cariñosa / Fría & $89,8 \%$ & $10,2 \%$ & Cariñosa (79,6\%) \\
\hline 18. Educada / Descortés & $88,1 \%$ & $11,9 \%$ & Educada (76,2\%) \\
\hline 19. Dura / Suave & $10,3 \%$ & $89,7 \%$ & Suave (79,4\%) \\
\hline 20. Agresiva / Pacífica & $7,5 \%$ & $92,5 \%$ & Pacífica (85\%) \\
\hline
\end{tabular}

Tabla 4. Resultados Kia mujer.

En el anuncio de la marca Kia protagonizado por el modelo masculino, observamos diferencias superiores al $50 \%$ en nueve de las parejas de valores que componen el cuestionario. Así, los valores valiente, fuerte, ganador, seguro, dominante, atrevido, serio, educado y duro superan en dicho porcentaje a las respuestas obtenidas para sus opuestos. Del mismo modo, los valores rebelde, joven, responsable, egoísta y callejero obtienen puntuaciones superiores al $20 \%$ si los comparamos con sus contrarios. Además, los términos tranquilo, individualista, sensual, frío y agresivo superan en porcentajes inferiores al $20 \%$ a sus antónimos.

En relación a las respuestas dadas por el alumnado al anuncio de automóviles Kia cuya protagonista es una mujer, se aprecian diferencias superiores al 50\% en doce parejas de valores contrapuestos. Concretamente, los términos débil, sumisa, joven, alegre, tranquila, 
sincera, sensual, generosa, cariñosa, educada, suave y pacífica obtienen puntuaciones superiores al $50 \%$ en comparación a sus opuestos. Asimismo, en las siete parejas de valores contrapuestos restantes, los términos cobarde, perdedora, insegura, atrevida, obediente, responsable, solidaria y hogareña son elegidos en porcentajes superiores al $20 \%$ que sus antónimos.

Estos resultados nos muestran que, pese a ser un mismo producto el que se anuncia, las respuestas varían en función de la persona que aparece en el anuncio, lo que, al mismo tiempo, nos muestra las concepciones de género que tiene el alumnado y la imagen de género que transmite la publicidad. Así, mientras que el protagonista masculino es identificado como ganador, fuerte, valiente, serio, duro o agresivo por citar algunos, al personaje femenino se asocian otros valores diferentes y opuestos a los anteriores. De este modo, si comparamos los resultados obtenidos en este anuncio con los resultantes de la aplicación del cuestionario al anuncio de Kia protagonizado por una mujer, se aprecia cómo el alumnado participante coincide al asociar valores al sexo femenino. Así, de las veinte parejas de valores contrapuestos, únicamente existe discrepancia en la no 6 (atrevidatímida), eligiéndose en los otros casos siempre un valor por encima de su opuesto. Además, llaman la atención los altos porcentajes obtenidos en ambos anuncios para los valores joven, alegre, tranquila, sincera, sensual, generosa, cariñosa, educada, suave y pacífica, así como la tendencia a asociar con la mujer los términos cobarde, débil, perdedora, responsable u hogareña.

\section{Conclusiones}

En primer lugar, podemos afirmar que la presencia de valores sociales y de género dentro de la imagen publicitaria es un hecho constatable. No obstante, conviene tener en cuenta que no todos los valores sociales y de género se encuentran en los anuncios, sino únicamente aquellos que sirven para la persuasión de los receptores como potenciales consumidores. En este sentido, no conviene olvidar que, mediante las estrategias persuasivas, el publicista pretende dotar de significados positivos al objeto anunciado, excluyendo del mismo toda referencia o connotaciones negativas que pudieran derivarse de su construcción icónica.

De este modo, y a partir del análisis de las respuestas obtenidas en nuestra investigación, se ha comprobado la aceptación general de valores genéricos que socialmente se entienden como positivos, como pueden ser ganador, seguro, valiente, atrevido, joven, sensual, sincero o moderno. Esta aceptación no hace sino reafirmar que el discurso publicitario no puede entenderse sin la componente persuasiva que se estudia detenidamente por parte de las compañías y las agencias publicitarias para hacer más atractivos sus productos. Y la estrategia de persuasión publicitaria se elabora excluyendo las posibles interpretaciones negativas que pudieran insinuarse en el mensaje publicitario, de ahí que los sujetos de la investigación no apuntaran valores negativos como pudieran ser perdedor, inseguro, cobarde, recatado, mayor, falso o anticuado. 
Además, para algunas de las parejas de valores contrapuestos (fuerte o débil, rebelde u obediente, serio o alegre, nervioso o tranquilo, responsable o despreocupado, individualista o solidario, egoísta o generoso, hogareño o callejero, cariñoso o frío, educado o descortés, duro o suave y agresivo o pacífico) aparecen respuestas para algunos de los términos anteriores que pudiéramos considerar negativas. Ello nos hace pensar que existen dos grupos diferenciados: por un lado, los valores genéricos que se encuentran presentes en la gran mayoría de los anuncios y que gozan de un alto grado de aceptación social y, por otro, los que se utilizan igualmente para dotar de significado al objeto anunciado, pero cuyo nivel de aceptación social varía en función de los sujetos o del género a los que va destinado el mensaje.

Asimismo, a partir de las respuestas obtenidas, podemos afirmar que el alumnado no solo utiliza valores diferentes para referirse a uno u otro género, sino que mediante ellos se reproducen modelos o estereotipos que contribuyen a mantener las diferencias entre hombre y mujer. En este sentido, los sujetos encuestados suelen otorgar puntuaciones más altas en los anuncios protagonizados por el modelo masculino en los valores valiente, fuerte, ganador, seguro, dominante, atrevido, rebelde, serio, nervioso, despreocupado, individualista, egoísta, callejero, frío, descortés, duro y agresivo. Sin embargo, en aquellos anuncios cuya protagonista es un personaje femenino, los valores con mayor presencia son cobarde, débil, perdedora, insegura, sumisa, recatada, obediente, alegre, tranquila, responsable, solidaria, hogareña, cariñosa, educada, suave y pacífica. Estos resultados no quedan muy lejos de lo apuntado por Rey (1994: 211) para quien "la dulzura, la ternura y la afectividad eran atributos exclusivamente femeninos. La competitividad, la fuerza y la ambición eran signos netamente masculinos".

Por los resultados obtenidos, entendemos que las imágenes publicitarias de los modelos masculinos y femeninos reiteran en los estereotipos fuertemente arraigados en el imaginario colectivo, pues, tal y como afirman García Fernández y García Reyes (2004: 47) "Ios estereotipos que la publicidad sostiene y refuerza se sustentan en una serie de convencionalismos iconográficos que se han introducido en la sociedad a lo largo de la historia". La explicación a la pervivencia de esos estereotipos había que buscarla en las concepciones tradicionales muy asentadas en nuestra sociedad acerca de los roles masculino y femenino. Así, y a pesar de las grandes transformaciones que se han producido en nuestra sociedad como resultado de una lucha a favor de la igualdad de los géneros, todavía pervive la idea del hombre como la persona responsable de la familia en cuanto que debe ser la que, a través del trabajo asalariado, permita el sustento de la misma. Para lograr tal objetivo, el hombre debía ser portador de valores como los sugeridos en los anuncios protagonizados por los personajes masculinos, o lo que es lo mismo, debía ser un individuo lo suficientemente fuerte, agresivo, duro y frío, a la vez que callejero, ganador, seguro, dominante o serio para obtener el éxito en su trabajo o pasar mucho tiempo alejado del hogar. Por el contrario, la idea tradicional de mujer la recluyó durante mucho tiempo dentro de las paredes del hogar, donde su misión era estar al servicio de la familia. Para el logro de tal objetivo, debía reunir 
valores como hogareña, cariñosa, alegre, obediente, insegura o sumisa, todos ellos al cuidado de los hijos y del mantenimiento del propio hogar. Esta conclusión coincide con las aportaciones de Garrido (2008), quien al analizar la publicidad de los años cincuenta afirma que el hombre publicitario trabaja fuera del hogar, tiene una serie de privilegios, genera ingresos o es autoritario y a veces agresivo, mientras que la mujer publicitaria es definida como trabajadora en el hogar, encargada de ser madre y esposa u objeto de deseo.

Como tercera conclusión, se ha podido comprobar el nivel de asignación de valores a los modelos masculino y femenino publicitarios por parte de los estudiantes del tercer ciclo de Educación Primaria. Las respuestas dadas a los cuatro anuncios propuestos nos llevan a concluir que, por un lado, los escolares muestran cierta homogeneidad en las respuestas aportadas para cada uno de los anuncios. Así, coinciden en la identificación de valores asociados al éxito, como son la modernidad, la victoria, la seguridad o la sensualidad en todos los anuncios. Por otro lado, comprobamos cómo determinados valores son elegidos para los anuncios protagonizados por modelos masculinos y otros, normalmente los opuestos, se reservan para las imágenes protagonizadas por personajes femeninos.

Llama finalmente la atención que, a pesar de los avances relacionados con la eliminación de estereotipos de género, el fenómeno publicitario mantenga en sus propuestas valores con contenido sexista, sin atender a las demandas sociales en el sentido de evitar los estereotipos especialmente ligados a la imagen femenina, aun sabiendo sus autores que el discurso publicitario ejerce una fuerte influencia en gran parte de la población, de modo muy especial entre los escolares, niños y adolescentes, que forman un sector fascinado por los modelos publicitarios y cuya futura personalidad, en formación durante esta etapa evolutiva, puede verse influenciada por la información transmitida a través de la publicidad.

\section{Referencias bibliográficAs}

CANO, Mercedes (2001): Hombre y mujer en la cultura tradicional española. Cuadernos de Cultura y Civilización Hispánicas. Actas, Madrid.

CORREA, Ramón, GUZMÁN, María Dolores y AGUADED, Ignacio (2000): La mujer invisible. Una lectura disidente de los mensajes publicitarios. Huelva, Grupo Comunicar.

EGUIZABAL, Raúl (2009): Industrias de la conciencia. Una historia social de la publicidad en España (1975- 2009). Barcelona, Pirámide.

GARCÍA FERNÁNDEZ, Emilio y GARCÍA REYES, Irene (2004): "Los estereotipos de mujer en la publicidad actual". Questiones Publicitarias, 9, 43-64. 
GARRIDO, Manuel (2008): "Redefinición de lo masculino y femenino en la publicidad actual", en Rey, Juan, Publicidad y sociedad. Un viaje de ida y vuelta. Comunicación Social, Sevilla, pp.187-213.

GONZÁLEZ i PAREDES, Jordi (2004): Usos actuales del marketing sensual. Iconos femeninos de la publicidad de hoy. Barcelona, Granica.

ORTIZ, Joaquín (2008): "El niño, los medios y la publicidad". Vox Paediatrica, 1, 39-43.

REY, Juan (1994): El hombre fingido. La representación de la masculinidad en el discurso publicitario. Fundamentos, Madrid.

REY, Juan (2008): "La publicidad, el efecto búmeran y la galería de los espejos", en Rey, Juan, Publicidad y sociedad. Un viaje de ida y vuelta. Comunicación Social, Sevilla, pp.11-19.

RACIONERO, Flora (2004): "Publicidad subliminal". ED.UCO, 3, 295-316.

RODRIGO MARTÍN, Luis (2011): Publicidad y consumo. Nuevas modas, viejas causas y valores sociales. Comunicación Social, Sevilla.

SÁINZ, Aureliano (2002): iMírame! Teoría y práctica de los mensajes publicitarios. Eneida, Madrid.

PACKARD, Vance (2007): The hidden persuarders. IG Publishing, Brooklyn.

RODRÍGUEZ, Carmen, MATUD, María Pilar y ESPINOSA, Inmaculada (2008): "Género y publicidad en la prensa diaria". Questiones Publicitarias, 13, 1-9.

SCHOR, Juliet B (2006): Nacidos para comprar: los nuevos consumidores infantiles. Paidós, Barcelona.

WOOD, Julia T (2009): Gendered lives: Communication, gender, and Culture (8a Ed.). Wadsworth Cengage Learning, Boston.

[Recibido: 17 de noviembre de 2013. Aceptado con cambios: 20 de octubre de 2014. Aceptación definitiva: 22 de diciembre de 2014]. 